\title{
The innovative nature of teaching methods from a historical retrospective viewpoint
}

\author{
Natalia Sukhova ${ }^{1, *}$, Lera Yurkina $^{2}$, and Elena Buslaeva ${ }^{2}$ \\ ${ }^{1}$ Moscow Region State University, 24, str. Vera Voloshina, 141014, Moscow region, Mytischi, Russia \\ ${ }^{2}$ Sciences Moscow State Linguistic University, st. Ostozhenka house 38, building 1, 119034, \\ Moscow, Russia
}

\begin{abstract}
The paperwork deals with the issues of innovative processes in modern education. The milestones of innovations are the integration of Russia into the international educational space and the relatively free standardization of education. The complex contradictory nature of the transformations is noted and traced on the example of pedagogical education in a historical retrospective. The paper discusses the main negative trends, many of which have already been a stumbling block in the history of pedagogy. Particular attention is paid to the reduction of the lecture component and the flat understanding of the educational process activation.
\end{abstract}

\section{Introduction}

The integration of Russia into the European educational space has led to many changes in the domestic educational sphere: educational legislation has changed, standards are being adopted and constantly modified, the list of specializations is being updated, educational literature is changing its format... However, the basis of educational innovation lies in the desire to transfer education, especially higher education, into the activity-oriented plane, to equip the graduates not only with fundamental knowledge, but also with methods of using it, as well as with the skills of updating the information system throughout their life. At the same time, educational organizations are given considerable freedom in ways to achieve their goals [1]. In the substantial aspect, neither disciplines nor their subject content are practically standardized, since these areas are defined by a set of competencies. However, in real situations of the educational programs and curricula creation, liberalism of standards sometimes leads to very sad tendencies.

The basis of higher education traditionally consisted in the reliance of the skills being formed on fundamental knowledge, which, as it was assumed, made it possible to solve non-standard problems as well, understanding their essence and refracting familiar solutions in a creative way, i.e. reaching the level of productive research activity. The knowledge-based learning model that existed for many decades implied memorizing large amounts of information, forming a certain set of practical operations and repeating them many times. Thus in most cases a specialist, well-trained to solve exactly standard

\footnotetext{
* Corresponding author: doptaganka@yandex.ru
} 
problems, came out. The competence-based model that is relevant today focuses on creative problem solving, integrating knowledge, skills and personal qualities. The main purpose of this approach is to improve the adaptive characteristics of a specialist.

Conducting a comparative analysis of the knowledge-based and competency-based models of education we can conclude that they have a common methodology - the reliance of the skills or integrated skills-competencies on fundamental knowledge. However, the competence-based model, first of all, allows freely to integrate learning and scientific research, which makes it possible, bypassing the usual stages of training, to go immediately to solving practice-oriented problems, combining elements of cognitive activity of a student and a scientist. Such problems can be solved by changing the methodology of teaching, for which it seems reasonable to change the methods of teaching at the university. In the words of D. I. Mendeleev: "Many forms of life have become new, and the forms of education have already become dilapidated, that the time has come to think about their improvement" [2]. Increasing the degree of problematical character of teaching methods, their transferring to the research plane, will ensure the direct entry of students into the world of science, which will shorten the cognitive paths and introduce a dynamic component into research activities. It is important to emphasize here that research has become an independent section of the Federal State Educational Standard of Higher Education.

One of the global problems of our time is innovative education, education for the future that actively adapting to the realities of practice. Therefore, within the framework of this study, we would like to turn to the teaching of pedagogy and look at the innovations that are offered to us today from the point of view of the methodological approaches already addressed in pedagogy history. What is happening with teacher education today? In this regard, it is important to note that pedagogy is one of the few sciences in which, from the moment of its separation into an independent system of knowledge to this day, there are disputes about the object and the subject of research and, sometimes, even the very independence of science is called into question. The name of the scientific branch is yet being debated, which is trying to be renamed into some faceless educational sciences.

Throughout its development history, pedagogy has experienced significant methodological difficulties, starting with the possibility of separating pedagogical theory from the array of philosophical knowledge and traditional philosophical questions "who is to be trained and why" and "what are the goals of education" and etc., ending with the modern discourse on the justification of attributing pedagogical specialization to a separate field of research, the possibility of delimiting psychological and pedagogical knowledge. We are told that pedagogy is outdated, that we don't need lectures anymore, but what we do need is new methods and forms, gamification, trainings and practice devoid of theory... There are many bright, beautiful terms, not always clear, often borrowed from foreign languages. What can you do, these are the laws of the market - it is only possible "to sell" an educational service if it feels slightly mysterious and strongly original. That's how innovative universities emerge, curricula are turned upside down, educational disciplines that are meaningless in fact, but selling: "educational technologies in selfeducation", "pedagogical didactics", "sports management", "active methods of social and psychological learning", "methodology of extracurricular educational activity" and etc. We are persistently taught that all the troubles of modern education come from its rigidity, that fast information flows no longer require fundamentalism, and the modern world is focused on the instructive nature of activities [3, 286-290].

There is a lot of talk about the need to activate the educational process. Unfortunately, most often it all comes down to minimizing or even eliminating lecture forms of teaching: their relative weight in the curriculum decreased in all educational organizations. In the wake of the pandemic a lot of even leading universities have made attempts to replace lecture communication with recordings posted in the cloud. Moreover, studies have already 
appeared proving that everything should be left as it is, i.e. lectures shouldn't be withdrawn from the online format, only seminars and workshops should stay in full-time. Nowadays trainings and workshops are honored. There is certainly nothing wrong with them, but they alone will not be able to solve the tasks assigned to higher education without a fundamental lecture component. A quite flatly understandable utilitarian approach prevails - to train only those skills that will be directly involved in the declared labor function. Here we would like to recall V. A. Sukhomlinsky: "In the world there is not only what is necessary, useful, but also beautiful. From the time a human became a human, from the moment when human gazed at the petals of a flower and the evening dawn, human began to gaze into himself. Human has comprehended beauty... Beauty and living thought are as organically united as the sun and flowers... The ideal of human beauty is at the same time the ideal of morality" [5], and we could recall the fable of I. A. Krylov, which tells about the growth of acorns. But do we care about beauty today? However, one should not understand beauty so literally, in this context it is rather the fundamental nature of education and its ideological character, rather than just the desire for an aesthetic perception of the world.

Another noteworthy social and innovative tendency is asserting that the modern global information system devalues education, since by one finger click children learn more than teachers in five years of university studies. Knowledge about facts is not yet a concept - not the facts themselves are important, but the conclusions that are based on them. However, the militant-minded amateurs-innovators did not stop there either - another negative tendency arose - the desire to blindly trust the information received, no matter from what source, and the unwillingness to at least somehow confirm or verify it. So many words were said about the need to teach students to extract information from various sources that everyone somehow forgot about the need for its verification and comprehension, and about critical thinking. The result was the depreciation of the value of educational literature and the replacement of textbooks with electronic resources, sometimes of very dubious content. A significant part of universities are connected to electronic libraries, where the selection of literature is subject to rather peculiar principles. Humanitarian literature suffered from this approach, the desire to flirt with the consumer led to the blurring of the lines between scientific literature and popular reading. So on the resource "University Library on-line" in the psychology section, the following books are found: V. Leonova "How to Raise Your Husband Properly", Ryhalskaya E. G. "Love in a Woman's Life: the Path from Parting and Loneliness to Mature Relationships", Anderson D., Schumann P. "The strategy of family life: how to wash the dishes less often, to have sex more often and quarrel less: a research book" $[6 ; 7 ; 8]$.

As with any innovative trend, there are good things and bad things. The good thing is the desire of competent approach to complement classical education with complete practical component. The bad thing is that on the wave of painful innovation one can repeat the mistakes that have already been considered and rejected in the historical experience of the development of pedagogy and pedagogical education.

\section{Materials and methods}

Based on the analysis of the current state of education, we have identified the following negative trends:

- getting classical fundamental disciplines out of the curricula - first of all, pedagogy - replacing it with instructive (integrating) disciplines (table 1)

- desiring to minimize, completely reduce or put into a record lecture forms of communication

- $\quad$ striving for education without textbooks 
Table 1. Analysis of the humanitarian component offered to bachelors studying in the chemical technology field.

\begin{tabular}{|l|c|c|c|c|c|}
\hline $\begin{array}{c}\text { Name of the } \\
\text { training } \\
\text { disciplines }\end{array}$ & $\begin{array}{c}\text { Classroom preparing: } \\
\text { lectures + seminars } \\
\text { (hours) }\end{array}$ & $\begin{array}{c}\text { Control } \\
\text { events }\end{array}$ & $\begin{array}{c}\text { Self-work } \\
\text { of } \\
\text { students } \\
\text { (hours) }\end{array}$ & $\begin{array}{c}\text { Total } \\
\text { hours } \\
\text { (hour } \\
\text { s)/c.u. }\end{array}$ & $\begin{array}{c}\text { Character of } \\
\text { Discipline: Funda } \\
\text { mental /variable } \\
\text { /instructive }\end{array}$ \\
\hline History & $16+16=32$ & exam & 40 & $108 / 3$ & fundamental \\
\hline $\begin{array}{l}\text { Jurisprudenc } \\
\text { e }\end{array}$ & $8+8=15$ & credit & 38 & $72 / 2$ & fundamental \\
\hline Philosophy & $32+32=64$ & exam & 44 & $144 / 4$ & fundamental \\
\hline $\begin{array}{l}\text { Worldview } \\
\text { unity of } \\
\text { humanitaria } \\
\text { n knowledge }\end{array}$ & 16 & credit & eleven & $36 / 1$ & Instructive \\
\hline $\begin{array}{l}\text { Historical } \\
\text { elective } \\
\text { disciplines }\end{array}$ & 16 & credit & 38 & $72 / 2$ & variable \\
\hline $\begin{array}{l}\text { Higher } \\
\text { education }\end{array}$ & $6+14=20$ & credit & 34 & $72 / 2$ & instructive \\
\hline $\begin{array}{l}\text { Individual } \\
\text { learning } \\
\text { paths }\end{array}$ & $6+8=14$ & credit & 40 & $72 / 2$ & instructive \\
\hline $\begin{array}{l}\text { Educational } \\
\text { technologies } \\
\text { in self- } \\
\text { education }\end{array}$ & 16 & credit & 38 & $72 / 2$ & instructive \\
\hline
\end{tabular}

In order to assess these trends and their impact on education, a retrospective analysis of teacher education development is proposed.

As the content of training courses in pedagogical disciplines was developed, teachers of higher and secondary educational organizations increasingly concentrated their attention on improving the organization and methods of teaching them. Since the end of the 1920s, intensive work has been developing in the field of teaching the pedagogical cycle disciplines.

The manual of the oldest Soviet teacher N. V. Chekhov should be considered an important milestone on this path [9]. It consists of an introduction and eight tasks. The introduction sets out the objectives of the course and the order of its study, gives a characteristic of teacher education in the RSFSR and the network of pedagogical educational organizations.

In the first task there are general questions of the methodology studied. The author clearly identifies three cycles of subjects in teacher training:

- general educational

- socio-political

- pedagogical

In the textbook offered to the reader, methods of teaching disciplines of the pedagogical cycle are considered. Their characterization is preceded by analysis of vocational education in the RSFSR, the organization of training school workers (term of the 1920-30s), the content and methods of teaching pedagogical disciplines, the ratio of theoretical and practical teacher's work.

The main attention, according to the author, should be concentrated on the study of the following methodological problems:

1. Oral teaching.

2. Seminars. 
3. Laboratory training system.

4. Pedagogical practice.

A significant place in the manual is given to the consideration of such issues as writing thesis, organizing knowledge, internship, self-accounting, etc.

Special consideration is given to the issues of accounting for practice and determining the qualifications of a teacher. Tasks contain basic information on the questions posed, they are presented concisely, available for self-studiers, and they allow a more detailed presentation of certain issues by teachers. The assignments end with self-test questions.

The manual is mainly addressed to teachers of pedagogical technical schools, who carried out teacher training for primary schools at that period, and as the author himself notes, it could also be used by teachers of higher pedagogical educational institutions. In particular, the second part of the textbook, which, from the author's point of view, was not the main one, could attract the attention of teachers of pedagogical universities.

N. V. Chekhov's "Methods of Teaching Pedagogical Subjects" can be viewed, on the one hand, as a definite result of searches in the field of teaching pedagogy, carried out throughout the $1920 \mathrm{~s}$, and, on the other hand, as a starting point for further improving the level of teaching pedagogy in the 1930s.

The improvement of the organization and methods of teaching pedagogy was carried out in close connection with general methodological searches.

In the pedagogical literature of the $1930 \mathrm{~s}$, along with traditional teaching methods, the project method and the team laboratory training method received wide coverage. By the beginning of the $30 \mathrm{~s}$, the tendencies of absolutization of these methods and their spread in secondary and higher education were clearly manifested. Gradually, new methods become dominant in teaching pedagogical subjects.

In the materials devoted to the result analysis of pedagogical universities review for the 1930-1931 academic year, it was noted: "In terms of teaching methods, in comparison with previous years, pedagogical universities have moved forward (the lecture method is being eliminated, laboratory classes with a free schedule are being introduced, attempts to switch to the project method have already emerged)" [10, 9-12].

A similar point of view extends to the use of seminars in the educational process of pedagogical institutes: "...in general, seminars as a form of work have obviously outlived their time: they made sense only as an addition to lecture courses. Since the introduction of active methods eliminates lecture courses where students only listened and wrote down where they did not work on the material on their own, because now, while taking all the courses, we consider it necessary to maximize the involvement of students in independent work on the material, as seminar being a form of work loses all meaning. Now we have to talk not about lecture courses, but only about general special courses in the same discipline, worked out with the same methods" [11, 39-40].

As in other academic subjects, pedagogy classes were based on independent tasks performance by students, organized in teams. This path was considered as the main one in the study of educational material on pedagogy. With such an organization of classes, teachers performed only controlling and advisory functions.

Supporters of the team laboratory method were guided by the attitude towards the development of students' independence, underestimating the role of the teacher in organizing the educational process. In practice, this led to lack of control in the organization of educational work and to the loss of organizational clarity in its construction.

In the decree of the Central Committee of the All-Union Communist Party "On curricula and regime in primary and secondary schools" (1932) the negative aspects of the team laboratory training method were revealed and the practice of its application as universal was condemned. The decree said: "Despite the Central Committee's instructions... that no method can be recognized as the main and universal method of learning, the so- 
called team laboratory method has become the mainstream in the practice of schools." In a number of schools, it became universal and was accompanied by the organization of permanent and obligatory teams, which led to perversions in the form of impersonality in educational work, to a decrease in the role of pedagogy and in many cases ignoring the individual work of each student" [12].

In the following document, adopted by the Central Executive Committee of the USSR "On curricula and regime in higher education and technical schools" (September 19, 1932) the use of the team laboratory method in its "modern, de facto form" [15] was recognized as inexpedient. The USSR obliged "all educational institutions while determining teaching methods to approach precisely, taking into account the qualifications of the teacher, the level of students training" [12].

After the publication of the directives, the team laboratory method was finally withdrawn from the practice of teaching in higher educational institutions. School teachers and university professors risked using that type of the educational activities, even in those cases where it was most expedient. This was the result of the harsh criticism of the Party organs, which was firmly established during this period, of the shortcomings and errors in the organization of educational work.

Soon after the publication of the decree of the Central Committee of the All-Union Communist Party on the work of universities and technical schools, a number of works on teaching methods in higher educational institutions were published in the pedagogical literature. In particular, they sharply criticized the opinion widespread among the teaching staff that only the content of the educational material is of decisive importance in the teaching process, and the methods and form of presentation are secondary. There was also an opposite point of view: "Well-thought-out curricula and programs of pedagogical universities are of great importance in the preparation of highly qualified teachers. But the success of this training depends not only on the content of teaching, but also on how teaching, those forms and methods by which they are equipped with knowledge and skills necessary for pedagogical work", noted S. N. Belousov [13, 72].

The first attempts to develop a theory of teaching methods based on new decisions of the party and government were carried out in teaching aids on pedagogy prepared by $\mathrm{M}$. M. Pistrak and P. N. Shimbirev (1934).

M. M. Pistrak noted in his manual: "The teaching method, in the most general sense of the word, we call the method of transferring knowledge and developing the skills and abilities of students. Teaching methods are a tool in the hands of the teacher, this is the way they act in relation to the student and the way a student works under the guidance of a teacher" [14]. P. N. Shimbirev considered teaching methods as a way "by means of which the teacher organizes and guides the work of students on their mastery of the basics of science" [15]. It is easy to see that both definitions reflect with varying degrees of completeness the idea of the two-sided nature of the learning process, emphasize the leading role of the teacher, combined with the active cognitive activity of the student.

From these positions the manual of M. M. Pistrak also reveals other questions of the theory of teaching methods. According to the author, they should:

1. Be in compliance with: the subject of study, students age, the conditions and environment of the school, educational equipment.

2. Ensure a conscious and solid mastery of systematic knowledge based on theory and practice. 141].

3. Increase the leading role of the teacher within the conscious activity of students [14,

P.N. Shimbirev, along with the listed requirements, added student skills of independent work on the basis of their interest, initiative and communist attitude towards learning; combining training with industrial labor on such a basis that all 
socially productive labor is subordinated to the educational goals of the school; developing the ability to apply the acquired knowledge and skills in the practice of socialist construction [15].

It should be noted that with a significant increase in attention to the role of methods in equipping students with solid knowledge, the pedagogical literature emphasized the importance of developing students' skills of independence, the ability to apply knowledge in practice. Teachers sharply criticized the desire to universalize certain teaching methods, their various use in the educational process was needed. "All searches for a single, main, universal method of educational work should be viewed as an attempt to replace the dialectical method. At the same time, none of the proposed teaching methods can exhaust and cover all the versatility of the pedagogical process and all the complexity of educational work", the book "Teaching Methods in Primary and Secondary School" noted $[16,8]$.

Many authors adhered to this point of view; moreover, they noted that "a variety of methods is a necessary condition for the development of the thinking of schoolchildren" [14].

The increased attention to the improvement of the theory of teaching methods had a great influence on the content of the work of higher education. In this regard, great changes have taken place in its activities:

1. Lectures, seminars, practical exercises, etc. began to be used again in the work practice of pedagogical institutes.

2. A clearer arrangement of teachers and a delineation of functions between professors and assistants were carried out.

3. Requirements for students' knowledge have increased.

4. The responsibility of teachers for the quality of students' knowledge began to increase.

5. Teachers began to prepare more thoroughly for training sessions.

6. Students thoroughly studied primary sources, works of pedagogical science classics, current pedagogical literature $[18,73]$.

At the All-Union meeting of the country's pedagogical universities, in the process of solving the issue of teaching methods, requirements were developed. They had to provide a systematic knowledge of pedagogy, the ability to independently approach the solution of pedagogical problems, and the link between pedagogical theory and pedagogical practice. At the meeting, a scheme for organizing the pedagogical process in the course of pedagogy was outlined. It was based on a lecture. Then there was an independent work of students, pro-seminar classes (conversation, checking the assimilation of lecture material, preparation for practical assignments), seminars and finally an excursion $[18,75]$.

After the team laboratory training method was removed from the practice of pedagogical universities, the lecture again took the leading place in the teaching system. The attention of pedagogy teachers was focused on theoretical issues development of lectures usage in teacher education.

\section{Results}

The literature of the 1930s reflected such cardinal issues of lecture teaching as the purpose of a lecture and its place in the educational process, pedagogical requirements for a lecture, a combination of lectures with other teaching methods.

E. N. Medynsky considered lecture as a form of transferring the educational material studied at the university to students, creating the basis necessary for other work forms of students with teachers. Revealing the importance of lectures as a leading teaching method in a higher educational organization, E. N. Medynsky wrote: "A good lecture gives students 
an attitude, methodically preparing them and highlighting the key points in the study of a known issue. The lecture orients students in the proper study of the literature, helping critically understand it. The lecture sets out the system of the science in the most concentrated manner, being the most economical way of teaching". And then: "The living word is stronger than the book. With the conviction and erudition, the lecturer directly influencing the students, masters the audience, increasing their attention, interest, and power of perception... The emotional moment of the lecture, combined with the cognitive, enhances the latter. The lecture has an educational value" [19, 27-28].

However, recognizing the lecture as the main method of educational work with students, objectively assessing its capabilities, the teachers noted that it is not a substitute for a textbook; it only prepares students to study the recommended literature in their specialty.

During the discussion of the lecture being a teaching method in higher pedagogical educational institutions, the statement about the complete passivity of the student in its process was reasonably criticized. The basis for such statements was a distorted interpretation of the process of listening and perception. Proponents of this approach viewed students' listening to lectures as a process of "pure perception", by analogy with listening to any conversation without an orientation toward assimilation, without carrying out mental work on the material. The talk about the so-called "pure perception" actually masked the refusal to analyze the intense mental activity of the students while listening to the lecture. Proponents of such a statement overlooked the fact that in the process of recording, the mental processing of the perceived material is certainly carried out and this determines the well-known logical operations (analysis, synthesis, etc.).

"That moment alone requires high activity on the part of the audience. This radically rebuilds the student's perception process from passive to highly active. It becomes so intense that it requires the student to even train a certain skill in order to be able to concentrate forces in the right way to simultaneously listen to and record the essential data sent from the lecturer", K. Kornilov and M. Feofanov noted [20, 4-8].

The formulation and scientific substantiation of the requirements for a lecture was of great importance for the improvement of lecture teaching. In general terms, it came down to the following:

- lecture is the main form of transferring the studied knowledge to students;

- it creates the basis necessary for other work forms of students with teachers;

- through lecture, students are introduced to independent work on sources;

- the general content of lectures is determined by the programs of university disciplines;

- while analyzing the content of a lecture, it is necessary, first of all, to pay attention to its scientific usefulness and ideological and political consistency;

- lecture must have a comprehensive justification and deep, flawless evidence;

- new scientific data and generalizations of best practices obtained by the lecturer from special studies and periodical literature are of great importance in lecture;

- not only recognized and finally developed issues but also debatable problems should be well-covered $[13,73]$.

In this regard, individual requirements for a teacher as a lecturer are formulated:

- university lecturers are not only teachers, but also researchers in their field of knowledge;

- they must introduce students to the scientific development of those problems on which they themselves are working;

- while considering a particular problem, they should cover not only the final conclusions and results, but also the way and method by which it was possible to reach these results, to obtain certain scientific conclusions [13, 73].

Along with the content development of the lectures, considerable attention was paid to the issues of the methodology of its conduct. 
In preparation for the lecture, the teacher was asked to carry out preliminary work according to the following plan:

1. Define and clearly formulate the topic of the lecture.

2. Make a short summary of the issues that are supposed to be covered in the lecture.

3. Pick up quotes, references, notes that will be used during the lecture [19].

One of the most important questions of the lecturing methodology is the systematic study question of each of them throughout the reading of the entire course. In the course of this work, it was envisaged: study.

I. Front-end conversation conference on the entire lecture and the literature indicated for

2. Front-end conversation conference on 2-3 key issues of the lecture, put forward for discussion by the teacher.

3. Practical laboratory exercises in disciplines requiring experimentation.

4. Seminars [19].

In order to activate the attention of students, both at the beginning and during the lecture, such techniques were used as writing a lecture plan with the main conclusions on the board, distributing notes before the lecture. Great importance in this regard was attached to the use of visual aids. As a necessary condition for better assimilation of the lecture material, arousing interest in its content, the connection of the lecture read with the previous one was considered. When considering the structure of the lecture, it was recommended to take into account the ratio of factual data and generalizations, it was proposed to strictly dose the amount of material, select it, guided by the principle of scientific value and the possibility of assimilation of this material by students in a certain period of time.

In the course of the practical work of the pedagogical institutes, the requirements for lectures in pedagogy were clarified and further developed. They were formulated as follows:

1. The lecture should give a systematic presentation of the entire amount of issues on the topic: in the process of presenting the material, special attention should be paid to the consideration of topics not covered in the literature.

2. In its content, it is necessary to introduce rich concrete material, reinforced by historical comparisons, illustrations, examples.

3. In the process of lecturing, one should use data from related sciences, in particular psychology and pedagogy, and take into account the age characteristics of schoolchildren in the interpretation of issues related to school practice.

4. The lecture should precede the study of the topic in group lessons, determine the content of the group work following it and be accompanied by the use of illustrative material. The lecture course was allocated half of the total number of hours provided for working with the teacher [19].

In the 1930-40s, many issues of lecture teaching were posed and successfully resolved. This could not but affect the practice of using lectures in the educational process of higher education.

Considering the lecture as the main form of organizing educational work in higher educational institutions, the teachers of the 1930 s paid great attention to other forms of education.

In connection with the restructuring of curricula and students in-depth independent work in some of pedagogical universities, the question of abandoning group classes in general pedagogy was raised preserving only a lecture course and a school workshop. For all the inconsistency of such a proposal, it was noted, however, that the group sessions in the form in which they were conducted in the early 1930s did not fulfill their tasks. In this 
regard, measures were developed to improve the methodology for conducting group exercises.

It was proposed to abandon the group lessons as purely repetitive in relation to the lecture course and literary material, while planning practical work clearly proceed from those tasks that can be solved with in-depth study of individual sections of the course, and combine group lessons with a workshop [22, 21].

In accordance with the new program, the Department of Pedagogy of the A. I. Herzen Pedagogical Institute proposed the following stages of group lessons:

1. Study of the works of the classics and directive materials. This work was recommended to be carried out while considering the first sections of the course (the subject of pedagogy, the basics of communist education, curricula and programs).

2. Observation and generalization of school experience. This type of student activity was supposed to be linked with an in-depth study of the issues of teaching and upbringing methods based on a combination with a workshop at school. The student's task at this stage of practical work was not only to directly observe, but also to develop the ability to correlate school material with literary data, to generalize and draw up conclusions in writing.

3. Conducting a little experimental work. Such work was not considered mandatory. It was recommended to associate it with issues of upbringing and teaching methods. The choice of the topic depended on the specific conditions and the interest of the teacher and student.

4. Study of specific school documents, conducting surveys. These events were considered very important for preparing the future teacher for participation in the social life of the school $[16,35]$.

A necessary condition for organizing students' practical work in accordance with the proposed stages was their organic connection with the school. Conducting group and practical classes was provided only after the theoretical presentation of this issue by the teacher. In the process of using practical elaboration as a teaching method, problems were revealed that required further study.

They consisted in searching for the optimal combination of group study with lecture work, ways to enrich the knowledge, skills and abilities of students (if the basis of lecture and homework was based on the activity of repetition and consolidation of the material, then for the correct organization of the group study it was required to enrich the knowledge and skills of students, teaching them to apply these skills, etc.). The question of the complete coverage of the material in the course of the group study was controversial [16, 36].

Pro-seminar classes became widespread in the work of pedagogical institutes in the 1930s and 1940s. "Under a proseminar one should understand such a form of group lessons with one student group, which, based on the elaboration of the program material, set themselves the task of equipping students with the skills they need both for seminars and, in general, for in-depth independent work on a subject (literary sources, processing of materials collected during practical classes, analysis of manuals and etc.), as well as the task of taking into account students' knowledge", noted Professor L. Raskin [23].

In the pedagogical literature, proseminar was considered as a teaching method that most fully reflects the specifics of higher education, characterizes the peculiarities of the methodology of educational work at a university, and corresponds to the level of training of students.

During the pro-seminar classes, it was supposed to replenish students' knowledge with specific material, teach them to independently work with this material and draw their own conclusions based on the studied additional literature [23]. 
In some cases, proseminar was viewed as the first stage of the seminar work. It was envisaged that this teaching method, in combination with students' independent work, should provide an in-depth assimilation of the material, the ability to use a pedagogical source [23].

In the practice of higher education in the first half of the 1930s, three types of proseminars became widespread:

1. Proseminar, which is practically reduced to the level of a regular high school lesson.

2. Proseminar, which is a deteriorated version of the teacher's lecture.

3. Proseminar, which covered the usual seminar classes with its name [23, 13].

The listed types of pro-seminar classes did not correspond to the tasks that faced them.

In order to improve the methodology of their implementation in the practice of higher pedagogical educational institutions, it was proposed to introduce the following types of group classes:

1. Work on literary works on certain issues of pedagogy.

The task of this activity was to teach students to read literary sources and teach them to use these sources. In the process of this work, the student had to learn:

a) to analyze the work on pedagogical issues;

b) to reveal the system of the author's pedagogical views;

c) to extract from this work valuable guidance for practice.

2. Analysis of general pedagogical and school documentation.

This student activity, directed and guided by a teacher, was intended to teach them independent usage of practical material, and to equip them with the method of processing pedagogical documents.

3. Review and analysis of teaching aids, school equipment, didactic material used in extracurricular activities. Such a proseminar was conducted in the form of laboratory exercises with the obligatory demonstration of various types of equipment and teaching aids.

4. Exercises on selected issues based on materials taken from pedagogy programs and school practice. Such classes were used in the study of didactic topics "Organizational forms of educational work" (lesson), "Methods of teaching at school" and were of great importance for preparing students for teaching practice.

5. Briefing for special practical classes at school in connection with the pro-seminar study of certain topics. The purpose of this work was to develop students' skills of critical attitude to the studied literature and its correct assessment.

In the process of this type of activity, students analyzed the correspondence of the textbook to the program and children's age, its scientific soundness, the connection of the studied material with the issues of socialist construction and the nature of this connection, structure (sections, their characteristics, tasks and exercises, rules and definitions, questions for repetition), volume, language (compliance with the age of children, correctness of speech, accuracy and concise definition) and external design of the textbook (format, font, paper, drawings), etc.

6. Processing of materials received as a result of practical assignments.

7. Hearing and discussion of students' reports on small topics, which are both the results of their work on literature and the processing of materials collected in the process of visiting and examining school lessons [23].

The next step in improving the methodology for conducting proseminars was the development of requirements for its program. They were formulated as follows:

1. The program of the proseminar should include such topics from the general program of the course that are not limited to lecture presentation and require additional study of the literature. 
2. The study of each topic should take at least 2-3 two-hour lessons so that the teachers can familiarize themselves with the work of a significant part of the students.

3. The program of the pro-seminar classes is preliminarily agreed with the program of the lecture course, in it it's necessary to formulate the topics of the classes and indicate the number of hours that are allocated to each topic.

Pro-seminar classes were conducted in the form of a detailed conversation on controversial or generalizing issues with the final word of the teacher, instructions on working with primary sources and organizing practical studies-surveys, collecting material and its design. Students' reports of a generalizing nature were also practiced in the form of an independent analysis of the material followed by discussion, consultations on the issues of working on school materials, historical documents, programs, and survey data [24, 15$]$.

Special attention was paid to the organization of student consultations. There were certain hours for them; they were mostly of an individual nature. The tasks of the consultation were not only to help the student, but also to establish the amount of his knowledge, methods and forms of independent work that he uses, a prerequisite for the consultation was the preliminary informing the teacher of the questions that the student planned to find out in its course. A consultation, like a lecture, was to become one of the forms of rapprochement between a teacher and students [18, 76-77].

Despite the considerable attention paid to the issues of improving the organization of pro-seminar classes, the methodology of their conduct continued to be considered as one of the "bottlenecks" in the practice of teaching higher education and the restructuring of proseminars on a new basis, coordination of actions in the development of this issue of all departments of pedagogical universities, were interpreted in pedagogical press as one of the primary tasks of higher education.

A seminar occupied an essential place in the educational process of higher pedagogical educational institutions during the 1930s. Many teachers paid great attention to the development of the methodology for conducting seminars. So, E. N. Medynsky considered the seminar as a kind of practical lesson and gave it the following characteristics: "The seminar is the most difficult, requiring a high mental level, the ability to work with a scientific book, the ability to experiment and possess some erudition in the studied science, a form of study at a pedagogical university. It requires students to work in depth on themselves. It develops the skills of scientific research work" [16, 21].

In the definition that Professor S. N. Polyansky, emphasizes the element of independence in the work of students, which carries a properly organized seminar: "The seminar pursues an in-depth study of the material using research work in varying degrees depending on the course and focuses on the independent work of students with the subsequent communication of its results on specific questions to a group under the guidance of a teacher" [25]. In the works of other authors, the seminar was considered as a certain intermediate stage for preparing students for research work. In the same article by E. N. Medynsky, it is noted: "A mandatory feature of the seminar is the development of the student's research skills" And then: "Each student performs two tasks:

1. Material one - the acquisition of knowledge on the entire program of the seminar and special one - in-depth study of any only issue of the program.

2. Formal one - the acquisition of scientific research skills" [26].

E. N. Medynsky especially emphasized that for a teacher the seminar is of particular importance for the opportunity to speak in front of an audience with a coherent, detailed presentation of the topic. "This aspect of the seminar - the ability to cover the topic in full, to present it consistently and systematically, to speak before the audience in a lively and interesting way - is extremely important for a teacher" [26].

Considering the seminar as one of the main forms of education in a higher educational institution, Soviet pedagogy made great efforts to develop a methodology for its conduct: a 
substantiation of options for its organization was given depending on the course in which it was conducted, on the degree of preparedness of students, the volume and content of the topic. The methodology for organizing the seminar also provided for pedagogical work: consultations, preparation of speakers, etc. In some cases, the seminar developed into a conference similar in nature to the training.

\section{Conclusions}

Along with the considered forms and methods of work, in the activities of pedagogical institutes, such as experimental study of the lesson, analysis of program and methodological documents, excursions, various types of practices were used, but they were interpreted as auxiliary and did not receive sufficient coverage in the pedagogical literature of the 1930s1940s.

It should be noted, however, that the departure from active teaching methods, carried out in the early 1930s and the withdrawal from the practice of both secondary and higher school of the team laboratory method, the project method, Dalton, as it was noted in the reporting documents, influence on the improvement of the educational process. However, the return to traditional teaching methods has spurred the efforts of academics and practitioners to improve their work.

It seems to us that the modernization of the teaching system does not necessarily require a radical destruction of the existing teaching system. Lots of new things, so necessary for us now, can be found by carefully looking into the old. In particular, the classification of teaching methods according to M N. Skatkin and I. Y. Lerner, offers as teaching methods that imply the highest levels of intellectual activity of students, partial-search and research one. The partial-search method assumes that students solve part of a real scientific problem under the supervision of teachers following by their commentary or group discussion. The research method - more complex - implies that students themselves find a problem area, state and solve a problem, and then submit it to the scientific community. Methodologically clear and pedagogically competent application of these teaching methods seems to us as able to solve many difficulties that arise when changing the knowledge paradigm of teaching to competence.

\section{References}

1. Portal of Federal State Educational Standards, http://fgosvo.ru/

2. D.I. Mendeleev, Cherished thoughts, http://iph.ras.ru/elib/Mendeleev_Zavetnye_mysli.html

3. L.V. Yurkina, Law and practice 3, 286-290 (2017)

4. N.M. Shulman, Sov. pedagogy 6, 48-61 (1938)

5. V.A. Sukhomlinsky, How to bring up a real person (Izhevsk, Udmurtia, 1980)

6. D. Anderson, P. Schumann, The strategy of family life: how to wash dishes less often, have sex more often and quarrel less: a research book (Moscow, Alpina Publisher, 2014) http://biblioclub.ru/index.php ? page = book_blocks \& view = main_ub

7. V. Leonov, How to raise your husband correctly: popular science edition (Kiev, Strelbitsky Multimedia Publishing House, 2013) http://biblioclub.ru/index.php?page=book\&id=234563

8. E.G. Rykhalskaya, Love in a woman's life: the path from parting and loneliness to mature relationships (Kiev, Strelbitsky Multimedia Publishing House, 2013) http://biblioclub.ru/index.php?page=book\&id=234418 
9. N.V. Chekhov, For ped. Frames 2, 9-12 (1931)

10. I.P. Kruglikov, Scientific. Worker 10, 39-40 (1930)

11. Public education in the USSR: Sat. documents (1917 - 1973) (M., 1974)

12. S.N. Belousov, Sov. Pedagogy 5 - 6, 72 - 90 (1937)

13. M.M. Pistrak, Pedagogy (M., 1934)

14. P.N. Shimbirev, Pedagogy (M., 1934)

15. E.N. Medynsky, Ped. Education 6, 76 - 81 (1934)

16. N.M. Shulman, Sov. Pedagogy 6, 48-61 (1938)

17. E.N. Medynskiy, Ped. Education 3, $26-33$ (1933)

18. N.N. Sukhova, Actual problems and innovative processes of general and vocational education. Sat. scientific works edited by L.P. Krivshenko (M., 2012)

19. L. Raskin Ped. Education 5, 12 - 21 (1934)

20. A.S. Bubnov, Transcript of the meeting of the Department of Pedagogy (Moscow State Pedagogical Institute, 1936)

21. A.S. Bubnov, Ped. education 3, 28 - 78 (1936)

22. S.N. Polyansky, Pedagogical education 5, 8-12 (1934)

23. E.N. Medynsky, Ped. education 5, 21 - 26 (1933) 